\title{
Business Intelligence in Industry 4.0: State of the art and research opportunities
}

\author{
Fanny-Eve Bordeleau \\ Business School, \\ Sherbrooke University \\ f-e.bordeleau@usherbrooke.ca
}

\author{
Elaine Mosconi \\ Business School, \\ Sherbrooke University \\ elaine.mosconi@usherbrooke.ca
}

\author{
Luis Antonio De Santa-Eulalia \\ Business School, \\ Sherbrooke University \\ 1.santa-eulalia@usherbrooke.ca
}

\begin{abstract}
Data collection and analysis have been at the core of business intelligence (BI) for many years, but traditional BI must be adapted for the large volume of data coming from Industry 4.0 (I4.0) technologies. They generate large amounts of data that need to be processed and used in decision-making to generate value for the companies. Value generation of 14.0 through data analysis and integration into strategic and operational activities is still a new research topic. This study uses a systematic literature review with two objectives in mind: understanding value creation through BI in the context of I4.0 and identifying the main research contributions and gaps. Results show most studies focus on real-time applications and integration of voluminous and unstructured data. For business research, more is needed on business model transformation, methodologies to manage the technological implementation, and frameworks to guide human resources training.
\end{abstract}

\section{Introduction}

Business intelligence has been improving the decision-making process in a variety of contexts for years [16]. The discipline is likely to be transformed in the wake of the fourth Industrial Revolution.

This fourth Industrial Revolution is currently underway [38], as acknowledged by the World Economic Forum in their annual meeting of 2016. Scientists from around the globe are dedicating resources to studying its impact on manufacturing companies. Some studies [3], [10], [19], [12], [27] cite economic factors, including fierce competition, as the leading reason to understand these changes. Technological drivers, such as product complexity [14], come second, followed by social factors, especially end consumers' changing requests [14] and mass customization [32].
The smart factory of Industry 4.0 generates a large volume of industrial data at a great speed. The recent increase in availability of sensors and acquisition systems has sparked interest in Cyber-Physical Systems applications [27], but the value creation coming from the usage of data has not received the same attention, as will be shown in this review. To ensure data can be converted to valuable insights, it needs to be integrated and analyzed, ideally in an automated fashion, to reduce manual work [21]. In this context, manufacturing companies have turned to data analysis to improve their decision-making processes [28]. Some companies chose to analyze maintenance related data to decrease the operating cost, while other reinvent their business model by selling data analysis on top of their conventional products. No matter how they chose to valorize data, to be able to face the harsh competitive and economic environment, this usage of data will need to lead to improved business performance.

In this paper, we are seeking to understand which aspects of business intelligence and data analysis can lead manufacturing companies to value creation, and to identify the main research contributions and gaps in BI literature on Industry 4.0. To this end, we have conducted a systematic literature review of business intelligence literature in the context of the fourth Industrial Revolution. Four databases, representing the main publications in business and engineering, were searched. Results show a great proportion of studies focus on real-time applications and integration of voluminous and unstructured data. They also highlight gaps in business related aspects, such as value creation or business model transformation, with most studies focusing on the technical aspects of Industry 4.0.

This paper is organized as follows. The next section provides the general research background. Subsequent sections detail the methodology, list the results of the systematic literature review, discuss the key findings and highlights the direction for further research. 


\section{Research background}

\subsection{Business intelligence}

Business intelligence (BI) is a broad concept including the collection, integration, analysis and visualization of organizational data to support and improve the decision-making process [16]. The phases of a BI initiative adapted from Eckerson [13] are presented in Figure 1. First, data is collected. Then, it is extracted, transformed and loaded (ETL) into the multidimensional database, usually a Data Warehouse, where it can be analyzed and presented [13]. Data presentation includes reports and interactive data discovery [21], alerts and operational graphical user interface [14] or dashboards [20],[21]. These phases rely on a technical architecture, often including a data warehouse.

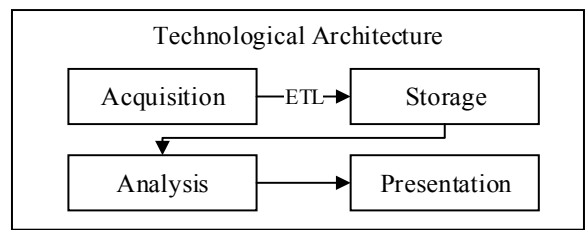

Figure 1. Phases of BI, adapted from Eckerson (2011)

The benefits of BI are mostly indirect. BI contributes to fact-based decision-making and helps improve the quality of information [16]. These improved decisions based on quality information then lead to enhanced business performance. On the other end, the technological improvements and new Cyber-Physical Systems offer new BI capabilities, such as predictive and adaptive indicators [3] which were not previously measurable. They can also facilitate and reduce the cost of real-time operational dashboards [14], a technology previously available but complex and cost-prohibitive.

\subsection{BI operational and strategic value creation}

BI can be used at any hierarchical level in the company: strategic, tactical or operational [13]. This paper will focus on the strategic and operational levels, leaving aside the tactical level which can sometimes be harder to distinguish from the other two. At the operational level, BI serves workers by monitoring processes [13], often with the help of performance indicators. At the strategic level, executives monitor, manage, and analyze business performance in accordance with the strategic objectives [13]. Strategic objectives supported by BI include new market development, major manufacturing technological investments or modifications to business models. Operational and strategic value are captured differently.
Fink et al. (2017) state that "operational value represents improvements in the efficiency of business process [...] whereas strategic value represents the ability to meet organizational objectives" (p.44). Manufacturing applications of BI, sometimes referred to as Manufacturing Intelligence [21], are often more operational in nature since they aim at improving floor plant decisions. Real time monitoring and analysis are two of the most popular applications, but this does not negate the use of operational information to improve business decision on a strategic level, such as competition related questions.

Operational BI capabilities are strongly related to operational value creation, but also lead to strategic value creation [16]. Thus, companies should dedicate resources to measuring strategic value even when only operational BI applications are implemented. This measure will contribute to situation awareness with respect to the execution of the business plan, and facilitate the business's transition into Industry 4.0.

\subsection{Industry 4.0 and the Smart Factory}

Industry 4.0 is a concept introduced by the German government to lead manufacturing companies into the fourth Industrial Revolution [28]. The core technologies of Industry 4.0 include sensors, communication protocols, cloud computing, cyber-physical systems, additive manufacturing, business intelligence and big data, and other emerging technologies. Most of these technologies are not recent innovations. However, it is the combination of technologies, business processes, and data processing that makes Industry 4.0 a novelty [2]. Schwab [38] expressed the need to understand how the fourth Industrial Revolution will reshape the "economic, social, cultural and human context in which we live" (p.2). Value creation for organizations will be achieved through innovative products and services, increased competitiveness and improved operational processes [2]. Although Industry 4.0 is only one of many governments led initiatives to guide companies through the current revolution, this paper uses it as a guideline because of the prevalence of the term in academic literature. Possible synonyms include smart manufacturing, the industrial internet and the smart factory.

Industry 4.0 manifests itself in many ways, the most prominent being the smart factory. A smart factory integrates autonomous computing and machine-tomachine communication to achieve a state of selfawareness and create self-learning machines [28]. This allows for better control of manufacturing processes, such as monitoring the remaining useful life of tools and equipment, increased uptime and better product quality [3], providing we can collect, analyze and use the data. 


\subsection{Reference Architecture: RAMI 4.0}

Since Industry 4.0 is a new concept, there is a need to develop a shared language and a structured framework. The Reference Architectural Model of Industry 4.0 (RAMI 4.0) is a three-dimensional model developed by a consortium led by the Association of German Engineers (VDI) and German Electrical and Electronic Manufacturers' Association (ZVEI) [1]. It is intended to assemble Industry 4.0 related standards. Figure 2 below is reproduced from Adolphs and Epple [1]. The cube is meant to represent horizontal integration of data in the value stream and vertical integration through an enterprise's hierarchical levels: product, field device, control devices, station, work center, enterprise, and the connected world.

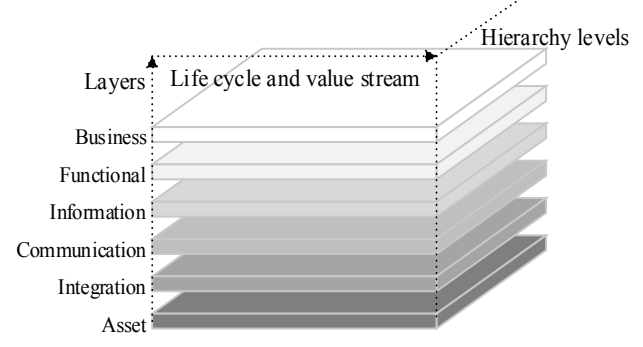

Figure 2. RAMI 4.0 adapted from Adolphs \& Epple (2017)

The layers are meant as a reminder to integrate all aspects of the enterprise in the digitalization, not only communication and information. For instance, a successful business intelligence application like a team leader's dashboard must integrate and compute data coming from assets such as equipment's sensors, communicate it to the dashboard and meet the requirements of the business layer, namely the business's senior management.

\section{Research Method}

To minimize bias in the selection of the articles included in this study, a systematic methodology was adopted. A systematic review is a transparent and reproducible search of the existing literature, in which great care is taken to apply objective criteria to the inclusion or rejection of an article [41]. Transparency and reproducibility is ensured by following the guidelines proposed by Tranfield, Denyer and Smart [41]. These guidelines consist of nine phases divided in three stages, as presented in Table 1.

Table 1. Stages of a systematic review, adapted from Tranfield et al. [41]

\begin{tabular}{|c|}
\hline Stage Phase \\
\hline 1. Planning the review \\
\hline 0. Identification of the need for a review \\
\hline 1. Preparation of a proposal \\
\hline 2. Development of review protocol \\
\hline 2. Conducting the review \\
\hline 3. Identification of studies \\
\hline 4. Selection of studies \\
\hline 5. Study quality assessment \\
\hline 6. Data extraction \\
\hline 7. Data synthesis \\
\hline 3. Reporting results \\
\hline 8. Report and recommendations \\
\hline 9. Getting evidence into practice \\
\hline
\end{tabular}

\subsection{Planning the review}

As previously mentioned in this paper, Industry 4.0 is still a relatively new subject in academic literature and there are gaps in business intelligence research on the subject. Thus, there is a need to grasp what has been investigated and what remains to be studied. We are especially interested in existing studies' mentions of value creation, operational and strategic. While developing the review proposal, the existing literature was searched. No other literature review on BI and Industry 4.0 was available at this time. The review protocol [41] included identification of the research question, the search criteria including dates and databanks to be searched, and the inclusion criteria. The protocol summary is presented in Table 2. More details are given in the following section.

Table 2. Review protocol summary

\begin{tabular}{|c|c|}
\hline Subject & Business intelligence in manufacturing in Industry 4.0 \\
\hline $\begin{array}{l}\text { Research } \\
\text { questions }\end{array}$ & $\begin{array}{l}\text { What are the gaps and research opportunities in business intelligence regarding Industry } 4.0 \text { for } \\
\text { manufacturing? Which aspects of business intelligence and data analysis can lead manufacturing } \\
\text { companies to value creation? }\end{array}$ \\
\hline Dates & from 2010 to extraction date (February 2017) \\
\hline Databanks & ABI/Inform, Business Search Complete, ScienceDirect, Scopus \\
\hline Search criteria & Peer reviewed; Full text included; English; Title, abstract and keywords OR All (except full text). \\
\hline Inclusion criteria & $\begin{array}{l}\text { Discusses at least one manufacturing activity in the following list: matter transformation, equipment } \\
\text { maintenance, plant warehouse management or explicit mention of manufacturing AND Discusses at least } \\
\text { one BI subject in the following list: decision making process or decision support (including data acquisi- } \\
\text { tion and storage), data quality, information display, performance monitoring, analytic or data analysis. }\end{array}$ \\
\hline Keywords (I4.0) & Industry 4.0, Industrie 4.0, Smart factory, Manufacturing intelligence, Industrial internet. \\
\hline Keywords (BI) & $\begin{array}{l}\text { Business intelligence, BI, Analytics, Data analysis, Data science, Monitoring, Surveillance, MES, } \\
\text { Manufacturing execution system, SCADA, Supervisory Control and Data Acquisition. }\end{array}$ \\
\hline
\end{tabular}




\subsection{Conducting the review}

The objective of this review is to identify studies that were conducted in the field, and determine any gaps and opportunities in business intelligence research in Industry 4.0, specifically those related to manufacturing. It consists of a systematic examination of peer reviewed and indexed scholarly articles or conference papers published between 2010 and January 2017 on the above-mentioned topics. The year 2010 was chosen as the earliest date since the Industry 4.0 concept was defined in Germany around 2011. The first architectural reference model for Industry 4.0 was published in 2015 [1] and was accepted as a standard by German standard association DIN in 2016.

The following keywords were used as synonymous for Industry 4.0: Industry 4.0, Industrie 4.0, smart factory, manufacturing intelligence, and industrial internet. The keywords related to business intelligence were: business intelligence, analytics, data analysis, data science, monitoring, surveillance, MES, manufacturing execution system, SCADA, supervisory control and data acquisition. Four electronic article databases were selected because they contain the main publications in business intelligence and information systems: ABI/Inform, Science Direct, SCOPUS and Business Source Complete. Whenever possible, the search was limited to the title, abstract or keywords. If this option was not available, the search was set to "all except full text". Only English publications were included.

To be included in the sample, the article had to correspond to the definition of $\mathrm{BI}$ as presented in section 2.1 , notably the project had to deal with information, and not just raw data. It also had to cover manufacturing operations, or manufacturing companies. Value creation was not considered an inclusion criteria since a sub-goal of this study is to determine to what extent the value creation is included in the articles.

The search yielded 299 publications which were exported to eliminate duplicates. They were then filtered first on abstract reading, and finally for a complete reading based on the inclusion criterion mentioned above. The study quality assessment was made during the complete reading. No articles were excluded based on the quality of the research method. Table 3 presents the filtering results, with 42 distinct articles fitting the inclusion criterion. Most of the rejected articles were excluded because they were focusing on very technical aspects, i.e. wireless communication protocol, database structure or design of new sensors. They were not considered BI research.

A backward search was only performed when necessary to understand the context of an article, and was not included in the studied publications.
Table 3. Articles filtering process

\begin{tabular}{|c|c|c|c|}
\hline \multicolumn{2}{|l|}{ Filtering stage } & Articles count \\
\hline Database extract & 299 \\
\hline ABI/Inform:10 & $\begin{array}{c}\text { Science } \\
\text { Direct: } 44\end{array}$ & $\begin{array}{c}\text { SCOPUS: } \\
185\end{array}$ & $\begin{array}{c}\text { Business } \\
\text { Source } \\
\text { Complete 60 }\end{array}$ \\
\hline Duplicate removal & & 248 \\
\hline Abstract reading & 97 \\
\hline Full article reading & 42 \\
\hline
\end{tabular}

During the reading of the full article, various information on the article's bibliometrics and content was tagged for analysis based on the research design, BI subject, RAMI4.0 layer, cited performance indicators and value creation measures or indicators. The results are presented in section 4 .

\section{Results}

\subsection{Bibliometric analysis}

The bibliometric analysis is based on five criteria: year of publication, journal or conference, authors, country of the principal author, and research design.

The distribution by publication year is detailed in Figure 3. Although the year filter was set to 2010, the earliest relevant articles were published in 2012. This is consistent with the emergence date of Industry 4.0. Interest in the subject seems to be growing significantly, although it should be noted that, for 2017, only January was included in the study.

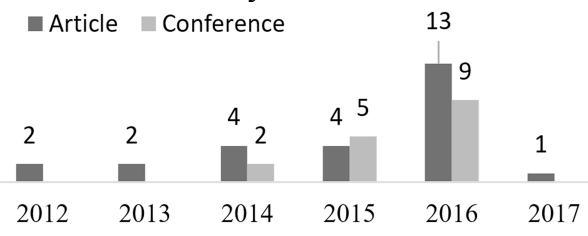

Figure 3. Distribution by publication year

A significant number of articles were conference proceedings. The 42 articles were distributed in 30 publication channel, journals or conferences. Three publication channels had at least three articles: ten articles were published through one of IEEE's channels, five were published in the conference proceedings of CIRP and three in the proceedings of the International Federation of Automatic Control.

The Industry 4.0 concept originally comes from Germany. Unsurprisingly, almost a quarter of the selected articles were published there. However, analysis of the articles by country of the principal author as illustrated in Figure 4 shows a growing interest in the manufacturing dependent countries of South-East Asia, as well as in the United States.

A clear majority of articles presented the creation of a physical or digital artefact, such as a database 
infrastructure or the programming of a dashboard. Some authors employed a conceptual design, notably in Cyber-Physical Systems architecture [27], [3].

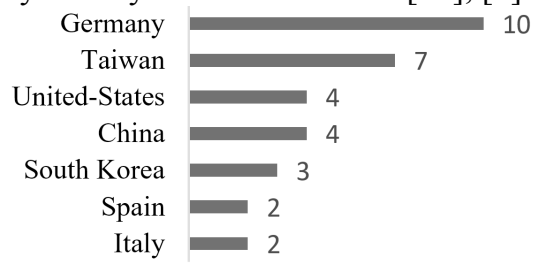

Figure 4. Country of the principal author

\subsection{Content analysis}

Analysis of BI and related technological aspect reveals 33 out of 42 articles included real time or near real-time data processing. In many of these articles, authors emphasized the technical difficulty of processing machine data in real time, because of database limitations [5], the integration of unstructured data [23], limits to the acceptable visual complexity [46] or the number of variables required to develop a sufficiently precise model [35], [45].

Nearly half of the articles presented data analysis applications, such as clustering [3],[45] or decision trees [10]. Figure 5 also shows 16 articles suggested a technological architecture without focusing on a single BI phase. For example, a technological framework using real time employee localization to adjust information display on a dashboard, which covers data acquisition, storage, analysis and presentation [24].

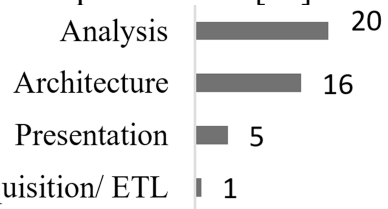

Figure 5. BI subject distribution

The classical BI architecture, relying on a data warehouse, cannot alone process unstructured or voluminous data in real or near real time [4]. Several authors have mentioned using Manufacturing Execution Systems (MES) to integrate data coming from different machines, devices and products [14], [21], [19] in real time. Data collected by the MES can then be used to feed dashboards, control cards or statistical algorithms.

Only three articles address the specific needs of Small and Medium-Sized Enterprises (SME). These companies often have limited financial and technological resources, and adopting a complete BI infrastructure is beyond their reach [12]. Several industrial domains were covered, notably aluminium [6], steel rolling [21] and flat steel [5], automotive parts [12], equipment manufacturing [33] and maintenance [48]. Strategic value creation measurement is underrepresented in the sample studies, being addressed in only three articles as shown in Table 4.

Table 4. Measure of value creation by BI in Industry 4.0 context

\begin{tabular}{|c|c|c|c|}
\hline Authors & Operational value & Strategic value & Method \\
\hline $\begin{array}{l}\text { Brandenburger et al. } \\
\text { [5] }\end{array}$ & $\begin{array}{l}\text { Rework reduction, cost reduction, improved } \\
\text { yield and improved quality }\end{array}$ & $\mathrm{n} / \mathrm{a}$ & Proof of concept \\
\hline Chen et al. [8] & $\begin{array}{l}\text { Reduced false alarms, improved catch rate } \\
\text { (quality measurements) }\end{array}$ & $\mathrm{n} / \mathrm{a}$ & Proof of concept \\
\hline Chien et al. [11] & Improved quality of operational decision-making & $\mathrm{n} / \mathrm{a}$ & Proof of concept \\
\hline Chien et al. [10] & $\begin{array}{l}\text { Improved efficiency by controlling process } \\
\text { variations, improved quality }\end{array}$ & $\mathrm{n} / \mathrm{a}$ & Proof of concept \\
\hline Chien et al. [9] & $\begin{array}{l}\text { Reduced material usage, reduced scrap, } \\
\text { improved productivity }\end{array}$ & $\mathrm{n} / \mathrm{a}$ & Proof of concept \\
\hline Dai et al. [12] & $\begin{array}{l}\text { Improved production efficiency, quality, and } \\
\text { timeliness of information, reduced paperwork, } \\
\text { operational errors, and work in progress } \\
\text { inventories }\end{array}$ & $\begin{array}{l}\text { Improved annual input, reduces } \\
\text { global costs and managerial } \\
\text { partiality, increase sales, } \\
\text { improved reputation }\end{array}$ & Proof of concept \\
\hline Eiskop et al. [14] & Improved productivity & $\mathrm{n} / \mathrm{a}$ & Proof of concept \\
\hline Engeler et al. [15] & $\begin{array}{l}\text { Reduced downtime, improved ease of use, } \\
\text { improved data detail }\end{array}$ & $\mathrm{n} / \mathrm{a}$ & Interviews \\
\hline Gröger et al. [19] & $\begin{array}{l}\text { Keeping human in the loop, learning } \\
\text { organisation }\end{array}$ & $\mathrm{n} / \mathrm{a}$ & Proof of concept \\
\hline Hänel \& Felden [21] & $\begin{array}{l}\text { Increased efficiency by reducing time to get data } \\
\text { and improved data quality, improved awareness } \\
\text { and data precision }\end{array}$ & $\mathrm{n} / \mathrm{a}$ & $\begin{array}{l}\text { Proof of concept } \\
\text { and interviews }\end{array}$ \\
\hline Kao et al. [22] & $\begin{array}{l}\text { Improved predictive overall equipment } \\
\text { effectiveness (OEE) }\end{array}$ & $\mathrm{n} / \mathrm{a}$ & Proof of concept \\
\hline Lee et al. [25] & Reduced cost by economies of scale & Reduced carbon footprint & Proof of concept \\
\hline Lee et al. [28] & Improved prediction of remaining useful life & $\mathrm{n} / \mathrm{a}$ & Proof of concept \\
\hline
\end{tabular}




\begin{tabular}{|c|c|c|c|}
\hline Authors & Operational value & Strategic value & Method \\
\hline $\begin{array}{l}\text { Neuböck \& Schrefl } \\
{[32]}\end{array}$ & $\begin{array}{l}\text { Improved agility by reacting more quickly to } \\
\text { change in orders }\end{array}$ & $\mathrm{n} / \mathrm{a}$ & Proof of concept \\
\hline Niño et al. [33] & $\begin{array}{l}\text { Reduced waste, improved return on production } \\
\text { process }\end{array}$ & $\mathrm{n} / \mathrm{a}$ & Proof of concept \\
\hline Oneto et al. [34] & Improved accuracy of data model & $\mathrm{n} / \mathrm{a}$ & Proof of concept \\
\hline Oses et al. [35] & Improved prediction of energy savings & $\mathrm{n} / \mathrm{a}$ & Proof of concept \\
\hline Shafiq et al. [39] & $\begin{array}{l}\text { Maintain just-in-time maintenance, improved } \\
\text { asset utilization, improved flexibility }\end{array}$ & $\mathrm{n} / \mathrm{a}$ & Proof of concept \\
\hline Tervonen et al. [40] & Improved data quality & $\begin{array}{l}\text { Boost new business models, } \\
\text { improved current product, } \\
\text { create new products }\end{array}$ & Proof of concept \\
\hline $\mathrm{Xu}$ et al. [46] & $\begin{array}{l}\text { Improved ease of use and perceived usefulness } \\
\text { of information, inefficiencies uncovered }\end{array}$ & $\mathrm{n} / \mathrm{a}$ & Interviews \\
\hline
\end{tabular}

Table 4 presents the 20 articles out of 42 mentioning operational value, strategic value or both. Operational value creation is measured in 20 articles. It is possible to assess BI value creation either objectively, i.e. by measuring the variation of a specific performance indicator over time, or subjectively, by interviewing users and managers. Objectives measurements were preferred in the majority of the articles. Most articles note better product or process quality after the BI project was implemented. Other benefits included reduced operating or maintenance costs, improved efficiency and increased data quality. The strategic benefits mentioned are increased sales, improved reputation, enhanced product quality and access to new business models. The favored method of success validation in the sampled articles is a proof of concept, where the project is implemented and the results assessed. Interviews were also used to measure the value created from the BI project, especially when the authors wanted to emphasize qualitative gains such as perceived ease of use [15], [46] and perceived data quality [21].

A common and objective way to assess operational value creation is to measure the variation of performance indicators. Figure 6 shows that the most popular indicators in the studied articles are quality rate, various cost reductions, production efficiency and uptime and yield.

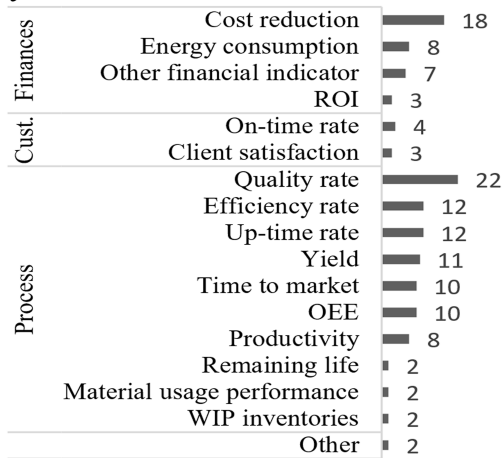

Figure 6. Cited performance indicators

The composite indicator overall equipment effectiveness (OEE) is cited in almost a quarter of all articles. Productivity is only cited in eight articles, despite being a common performance measure in operations management.

Among the authors who mentioned value creation, four had the objective of making the necessary information available or more easily accessible, and four others mentioned changes in processes at a higher level. As shown in Figure 7, most articles had the goal of improving the function of the asset being worked on. No articles only covered communication, integration or assets in the articles mentioning value creation. Table 5, available on appendix, provides a brief description of each selected article and its covered RAMI corresponding layer.

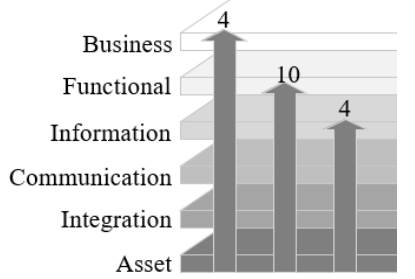

Figure 7. Architecture layer distribution

\section{Discussion and conclusion}

This study pointed out research gaps and opportunities in Industry 4.0's literature on business intelligence regarding business related issues such as value creation. A total of 42 articles were identified through a systematic literature review. Results show real time monitoring and analysis were the most common BI applications, but very few articles referred to the operational or strategic value of BI applications.

Although authors included in this review cited global competition and increasingly demanding customers as drivers for the implementation of Industry 4.0 projects, most failed to demonstrate how their projects helped companies reach their strategic objectives. Industry 4.0 relies on disruptive innovations and changes in business models and aims to offer 
companies a competitive edge in a world where consumers are looking for quality and customization while preserving mass production costs and delays [38]. However, only one author referred to new business model improvements [40]. Furthermore, as demonstrated in the previous section, BI research in Industry 4.0 has focused primarily on operational capabilities and has mostly measured operational value creation. Performance indicators such as quality rates and costs reduction are the most common measures of operational value in the cited articles. Strategic value for a company can be influenced by better operational capabilities [16], but we need to demonstrate the link between the project and the company's goals.

A possible explanation for the lack of value creation measurement is that research in the field is currently led by technically-focused engineering schools, opening up opportunities for business intelligence researchers. Several authors mention that there is still a need to validate their concept in a real manufacturing setting, implying the project was not based on a specific company and its strategic planning.

Overall, the bibliometric analysis shows a rising interest in business intelligence in the wake of the various Industry 4.0 related initiatives, especially in countries where the manufacturing sector represents a large proportion of GDP. The most common research methodology is design science research, showing that research in business intelligence adapted to Industry 4.0 is still diverging on new concepts, but there are also opportunities for confirmatory research.

Out of 42 articles, 33 included usage of data on a real or near-real-time basis. This is consistent with the smart factory concept, where the product, machine, building, and workers exchange data continuously. However, the benefits of real-time data analysis or monitoring have yet to be demonstrated, since few papers provided objective results. This integration of data along the hierarchical axis of RAMI4.0 is well covered in the selected literature. However, only a handful of articles mention the importance of communicating information through all layers of the company, up to the business level, in order to adapt the processes. This point will need to be corrected to ensure companies can validate value creation for the entire company and not just for the manufacturing function.

Technological limitations such as insufficient database infrastructure [5] or the complexity of integrating real time data [23] were cited by some authors as limitations in data integration and analysis in manufacturing processes. This is reflected in the number of articles focusing on the proposition of a standardized manufacturing BI architecture capable of real-time analysis. Several frameworks have been suggested, expanding on the classical BI architecture to include voluminous and unstructured data. However, most articles mention the need for extensive testing on their proposed architecture. They also need to integrate information with all layers of the enterprise, as suggested in RAMI 4.0.

This study identified several gaps or research opportunities in BI literature focusing on manufacturing and Industry 4.0. Notably, there is a need to evaluate the various developed architectures, their differences and common features, and suggest and validate a unified technological architecture for BI in Industry 4.0, one which is usable in different contexts. Another research opportunity is the confirmation of value creation for companies in the integration and analysis of real-time manufacturing data. Similarly, unstructured or voluminous data are gaining in popularity in manufacturing, but research on the subject remains anecdotal. Yet another subject to be covered is the validation of the value creation measures, notably performance indicators, to ensure those used in the academic literature are representative of the one used in practice. Finally, to achieve the goals of augmented competitive advantage through Industry 4.0 concepts, innovative projects are underway, both in the corporate world and in academia. Most of the selected articles did not mention innovation management capabilities or organization learning in manufacturing companies; many aspects remain to be studied, including the impact of Industry 4.0 technological projects on organizations with various dominant organisational learning mode.

At the moment, based on the literature, it is not possible to generalize about the value for the business created by BI applications in Industry 4.0, considering the lack of success measure in the selected articles. There is a need for a value creation framework adapted to $\mathrm{BI}$ and manufacturing in a context of rapid technological changes. This framework should include both objective measures of success such as performance indicator variations, and subjective measures such as perceived success. It should also include measurement of strategic value creation, to ensure companies achieve their strategic objectives. This suggests opportunities for future empirical and longitudinal studies.

There are limitations to this research. Several articles were excluded because they only covered technical aspects of data collection, such as sensor development or communication protocols, and, thus, did not meet the inclusion criterion. Furthermore, only English publications were included. As the subject is still emergent, publications were selected from several sources, including smaller conferences. This diversity made comparison of the articles' structure and quality more complex. A further improvement would be to analyse articles based on tactical or managerial levels, in addition to operational and strategic levels. Future 
work will focus on the business intelligence aspects of value creation through the use of BI in Industry 4.0 projects.

\section{References}

[1] Adolphs, P., and U. Epple, "Status Report: Reference Architecture Model Industrie 4.0 (RAMI4.0)", zvei.org, 2017. https://www.zvei.org/fileadmin/user_upload/Themen/

Industrie_4.0/Das_Referenzarchitekturmodell_RAMI_4.0_un d_die_Industrie_4.0-

Komponente/pdf/5305_Publikation_GMA_Status_Report_Z VEI_Reference_Architecture_Modē.pdf

[2] Anderl, R., and J. Fleischer, Guideline Industrie 4.0: Guiding principles for the implementation of Industrie 4.0 in small and medium sized businesses, VDMA Industries 4.0 forum, 2015.

[3] Bagheri, B., S. Yang, H.-A. Kao, and J. Lee, "Cyberphysical systems architecture for self-aware machines in industry 4.0 environment", IFAC-PapersOnLine 28(3), 2015, pp. 1622-1627.

[4] Biswas, S., and J. Sen, "A Proposed Architecture for Big Data Driven Supply Chain Analytics.”, IUP Journal of Supply Chain Management 13(3), 2016, pp. 7-33.

[5] Brandenburger, J., V. Colla, G. Nastasi, F. Ferro, C. Schirm, and J. Melcher, "Big Data Solution for Quality Monitoring and Improvement on Flat Steel Production", IFAC-PapersOnLine 49(20), 2016, pp. 55-60.

[6] Cao, B., Z. Wang, H. Shi, and Y. Yin, "Research and practice on Aluminum Industry 4.0", (2015), 517-521.

[7] Chen, Y., G.M. Lee, L. Shu, and N. Crespi, "Industrial internet of things-based collaborative sensing intelligence: Framework and research challenges", Sensors (Switzerland) 16(2), 2016.

[8] Chen, Y.-J., C.-Y. Fan, and K.-H. Chang, "Manufacturing intelligence for reducing false alarm of defect classification by integrating similarity matching approach in CMOS image sensor manufacturing", Computers and Industrial Engineering 99, 2016, pp. 465-473.

[9] Chien, C.-F., A.C. Diaz, and Y.-B. Lan, "A data mining approach for analyzing semiconductor MES and FDC data to enhance overall usage effectiveness (OUE)", International Journal of Computational Intelligence Systems 7(SUPPL.2), 2014, pp. 52-65.

[10] Chien, C.-F., C.-Y. Hsu, and P.-N. Chen, "Semiconductor fault detection and classification for yield enhancement and manufacturing intelligence", Flexible Services and Manufacturing Journal 25(3), 2013, pp. 367-388.

[11] Chien, C.-F., S.-C. Hsu, and Y.-J. Chen, "A system for online detection and classification of wafer bin map defect patterns for manufacturing intelligence", International Journal of Production Research 51(8), 2013, pp. 2324-2338.

[12] Dai, Q., R. Zhong, G.Q. Huang, T. Qu, T. Zhang, and T.Y. Luo, "Radio frequency identification-enabled real-time manufacturing execution system: a case study in an automotive part manufacturer.", International Journal of Computer Integrated Manufacturing 25(1), 2012, pp. 51-65.
[13] Eckerson, W., Performance Dasboards: Measuring, monitoring, and managing your business, John Wiley \& Sons, Hoboken, 2011.

[14] Eiskop, T., A. Snatkin, K. Kõrgesaar, and J. Søren, "Development and application of a holistic production monitoring system", (2014), 85-91.

[15] Engeler, M., D. Treyer, D. Zogg, K. Wegener, and A. Kunz, "Condition-based Maintenance: Model vs. Statistics a Performance Comparison", Factories of the Future in the digital environment - Proceedings of the 49th CIRP Conference on Manufacturing Systems 57, 2016, pp. 253-258.

[16] Fink, L., N. Yogev, and A. Even, "Business intelligence and organizational learning: An empirical investigation of value creation processes", Information \& Management 54(1), 2017, pp. 38-56.

[17] Fleischmann, H., J. Kohl, and J. Franke, “A Modular Architecture for the Design of Condition Monitoring Processes", Factories of the Future in the digital environment - Proceedings of the 49th CIRP Conference on Manufacturing Systems 57, 2016, pp. 410-415.

[18] Fleischmann, H., J. Kohl, and J. Franke, "A reference architecture for the development of socio-cyber-physical condition monitoring systems", (2016).

[19] Gröger, C., L. Kassner, E. Hoos, et al., "The data-driven factory leveraging big industrial data for agile, learning and human-centric manufacturing", (2016), 40-52.

[20] Groger, C., and C. Stach, "The mobile manufacturing dashboard", (2014), 138-140.

[21] Hänel, T., and C. Felden, "Applying Operational Business Intelligence in production environments", (2016), 365-377.

[22] Kao, Y.-T., S.-C. Chang, S. Dauzere-Peres, and J. Blue, "Opportunity for improving fab effectiveness by predictive overall equipment effectiveness (POEE)", (2016).

[23] Kassner, L.B., and B. Mitschang, "MaXCept - Decision support in exception handling through unstructured data integration in the production context: An integral part of the smart factory", (2015), 1007-1016.

[24] Khaleel, H., D. Conzon, P. Kasinathan, et al., "Heterogeneous applications, tools, and methodologies in the car manufacturing industry through an iot approach", IEEE Systems Journal PP(99), 2015.

[25] Lee, C.K.M., C.L. Yeung, and M.N. Cheng, "Research on IoT based Cyber Physical System for Industrial big data Analytics", (2016), 1855-1859.

[26] Lee, H., S. Yoo, and Y.-W. Kim, "An energy management framework for smart factory based on contextawareness", (2016), 685-688.

[27] Lee, J., B. Bagheri, and H.-A. Kao, "A Cyber-Physical Systems architecture for Industry 4.0-based manufacturing systems", Manufacturing Letters 3, 2015, pp. 18-23.

[28] Lee, J., H.-A. Kao, and S. Yang, "Service Innovation and Smart Analytics for Industry 4.0 and Big Data Environment", Product Services Systems and Value Creation. Proceedings of the 6th CIRP Conference on Industrial Product-Service Systems 16, 2014, pp. 3-8. 
[29] Lee, R., I.-Y. Chen, and P. Nichols, “A novel production process modeling for analytics", International Journal of GEOMATE 11(2), 2016, pp. 2370-2377.

[30] Leitão, P., J. Barbosa, A. Pereira, J. Barata, and A.W. Colombo, "Specification of the PERFoRM architecture for the seamless production system reconfiguration", (2016), 57295734.

[31] Miškuf, M., and I. Zolotová, “Application of business intelligence solutions on manufacturing data", (2015), 193197.

[32] Neuböck, T., and M. Schrefl, "Modelling knowledge about data analysis processes in manufacturing", IFACPapersOnLine 28(3), 2015, pp. 277-282.

[33] Nino, M., J.M. Blanco, and A. Illarramendi, "Business understanding, challenges and issues of Big Data Analytics for the servitization of a capital equipment manufacturer", (2015), 1368-1377.

[34] Oneto, L., D. Anguita, A. Coraddu, T. Cleophas, and K. Xepapa, "Vessel monitoring and design in industry 4.0: A data driven perspective", (2016).

[35] Oses, N., A. Legarretaetxebarria, M. Quartulli, I. Garc $\tilde{A}-a$, and M. Serrano, "Uncertainty reduction in measuring and verification of energy savings by statistical learning in manufacturing environments", International Journal on Interactive Design and Manufacturing 10(3), 2016, pp. 291-299.

[36] Park, S., "Development of Innovative Strategies for the Korean Manufacturing Industry by Use of the Connected Smart Factory (CSF)", Promoting Business Analytics and Quantitative Management of Technology: 4th International Conference on Information Technology and Quantitative Management (ITQM 2016) 91, 2016, pp. 744-750.

[37] Rix, M., B. Kujat, T. Meisen, and S. Jeschke, "An Agile Information Processing Framework for High Pressure Die Casting Applications in Modern Manufacturing Systems", Research and Innovation in Manufacturing: Key Enabling Technologies for the Factories of the Future-Proceedings of the 48th CIRP Conference on Manufacturing Systems 41, 2016, pp. 1084-1089.

[38] Schwab, K., The fourth industrial revolution, Crown Business, New York, 2016.
[39] Shafiq, S.I., G. Velez, C. Toro, C. Sanin, and E. Szczerbicki, "Designing Intelligent Factory: Conceptual Framework and Empirical Validation", Knowledge-Based and Intelligent Information \& Engineering Systems: Proceedings of the 20th International Conference KES-2016 96, 2016, pp. 1801-1808.

[40] Tervonen, J., V. Isoherranen, and M. Heikkila, “A review of the cognitive capabilities and data analysis issues of the future industrial Internet-of-Things", (2015), 127-132.

[41] Tranfield, D., D. Denyer, and P. Smart, "Towards a Methodology for Developing Evidence-Informed Management Knowledge by Means of Systematic Review", British Journal of Management 14(3), 2003, pp. 207-222.

[42] Wang, H., O.L. Osen, G. Li, W. Li, H.-N. Dai, and W. Zeng, "Big data and industrial Internet of Things for the maritime industry in Northwestern Norway", (2016).

[43] Wang, S., J. Wan, D. Li, and C. Zhang, "Implementing Smart Factory of Industrie 4.0: An Outlook", International Journal of Distributed Sensor Networks 2016, 2016.

[44] Wieland, M., P. Hirmer, F. Steimle, et al., "Towards a Rule-based Manufacturing Integration Assistant", Factories of the Future in the digital environment - Proceedings of the 49th CIRP Conference on Manufacturing Systems 57, 2016, pp. 213-218.

[45] Wuest, T., C. Irgens, and K. Thoben, "An approach to monitoring quality in manufacturing using supervised machine learning on product state data", Journal of Intelligent Manufacturing 25(5), 2014, pp. 1167-1180.

[46] Xu, P., H. Mei, L. Ren, and W. Chen, "ViDX: Visual Diagnostics of Assembly Line Performance in Smart Factories", IEEE Transactions on Visualization and Computer Graphics 23(1), 2017, pp. 291-300.

[47] Yoon, J.-S., S.-J. Shin, and S.-H. Suh, "A conceptual framework for the ubiquitous factory.", International Journal of Production Research 50(8), 2012, pp. 2174-2189.

[48] Yu, H.-C., K.-Y. Lin, and C.-F. Chien, "Hierarchical indices to detect equipment condition changes with high dimensional data for semiconductor manufacturing", Journal of Intelligent Manufacturing 25(5), 2014, pp. 933-943.

\section{Appendix}

\begin{tabular}{|c|c|c|c|}
\hline \multicolumn{4}{|c|}{ D. A } \\
\hline Authors & Description & Cited gaps or limits & RAMI4.0 layer \\
\hline Bagheri et al. [3] & Adaptive clustering for self-adjusting machines & $\mathrm{n} / \mathrm{a}$ & $\mathrm{n} / \mathrm{a}$ \\
\hline Biswas \& Sen [4] & $\begin{array}{l}\text { Propose a supply chain architecture for classical and } \\
\text { big data based analytics }\end{array}$ & $\begin{array}{l}\text { Need to adapt communication } \\
\text { protocol based on application }\end{array}$ & Information \\
\hline $\begin{array}{l}\text { Brandenburger et } \\
\text { al. [5] }\end{array}$ & $\begin{array}{l}\text { Analytics for visual quality monitoring in flat steel } \\
\text { production }\end{array}$ & $\begin{array}{l}\text { Limited by existing database } \\
\text { infrastructure }\end{array}$ & Integration \\
\hline Cao et al. [6] & $\begin{array}{l}\text { Architecture for production monitoring in aluminum } \\
\text { industry }\end{array}$ & Need to validate in practice & Functional \\
\hline Chen et al. [7] & $\begin{array}{l}\text { Propose guidelines for collaborative sensing } \\
\text { intelligence }\end{array}$ & $\begin{array}{l}\text { Several issues to be addressed: } \\
\text { data integration, mining, real } \\
\text { time algorithm development, etc. }\end{array}$ & Information \\
\hline Chen et al. [8] & $\begin{array}{l}\text { Analytics for reduction of false positive in defect } \\
\text { detection }\end{array}$ & $\begin{array}{l}\text { Room for model further } \\
\text { improvement }\end{array}$ & Information \\
\hline Chien et al. [9] & Data mining for production process improvement & $\begin{array}{l}\text { Room for model further } \\
\text { improvement }\end{array}$ & Information \\
\hline
\end{tabular}




\begin{tabular}{|c|c|c|c|}
\hline Authors & Description & Cited gaps or limits & RAMI4.0 layer \\
\hline Chien et al. [10] & $\begin{array}{l}\text { Detection and classification of defects for yield } \\
\text { enhancement }\end{array}$ & $\begin{array}{l}\text { Improve model to account for } \\
\text { more variables }\end{array}$ & Information \\
\hline Chien et al. [11] & $\begin{array}{l}\text { Real time identification and classification of } \\
\text { manufacturing defects }\end{array}$ & $\begin{array}{l}\text { Room to improve with a larger } \\
\text { data set }\end{array}$ & Information \\
\hline Dai et al. [12] & Case study of RFID real-time tracking in a shop floor & $\mathrm{n} / \mathrm{a}$ & $\mathrm{n} / \mathrm{a}$ \\
\hline Eiskop et al. [14] & $\begin{array}{l}\text { Production monitoring system architecture adapted } \\
\text { for SME }\end{array}$ & $\begin{array}{l}\text { Needs to be tested in a } \\
\text { manufacturing environment }\end{array}$ & Functional \\
\hline Engeler et al. [15] & $\begin{array}{l}\text { Comparison of model based and statistical based } \\
\text { condition monitoring }\end{array}$ & Large scale validation to be done & Functional \\
\hline $\begin{array}{l}\text { Fleischmann et al. } \\
\text { [17] }\end{array}$ & $\begin{array}{l}\text { Architecture for machine condition monitoring to } \\
\text { lower workers' cognitive overload }\end{array}$ & $\mathrm{n} / \mathrm{a}$ & $\mathrm{n} / \mathrm{a}$ \\
\hline $\begin{array}{l}\text { Fleischmann et al. } \\
\text { [18] }\end{array}$ & $\begin{array}{l}\text { Architecture for socio-cyber-physical systems in } \\
\text { machine condition monitoring }\end{array}$ & $\mathrm{n} / \mathrm{a}$ & $\mathrm{n} / \mathrm{a}$ \\
\hline $\begin{array}{l}\text { Gröger \& Stach } \\
{[20]}\end{array}$ & Real time mobile dashboard for manufacturing & $\mathrm{n} / \mathrm{a}$ & $\mathrm{n} / \mathrm{a}$ \\
\hline Gröger et al. [19] & $\begin{array}{l}\text { Architecture for a data-driven factory and application } \\
\text { scenarios }\end{array}$ & $\begin{array}{l}\text { Need to investigate the resulting } \\
\text { competitive advantage }\end{array}$ & Business \\
\hline $\begin{array}{l}\text { Hänel \& Felden } \\
\text { [21] }\end{array}$ & Architecture for real time operational BI & $\begin{array}{l}\text { Need further evaluation and } \\
\text { examples to be generalized }\end{array}$ & Functional \\
\hline Kao et al. [22] & Introduce predictive indicator for plant performance & $\mathrm{n} / \mathrm{a}$ & $\mathrm{n} / \mathrm{a}$ \\
\hline $\begin{array}{ll}\text { Kassner } & \& \\
\text { Mitschang [23] }\end{array}$ & $\begin{array}{l}\text { Integration of unstructured data in exception } \\
\text { handling architecture }\end{array}$ & $\begin{array}{l}\text { Complexity of integrating } \\
\text { unstructured data in real time }\end{array}$ & Integration \\
\hline Khaleel et al. [24] & $\begin{array}{l}\text { Various industrial IoT applications examples and } \\
\text { related frameworks }\end{array}$ & $\mathrm{n} / \mathrm{a}$ & $\mathrm{n} / \mathrm{a}$ \\
\hline Lee et al. [25] & $\begin{array}{l}\text { Architecture for big data analysis including external } \\
\text { data }\end{array}$ & $\mathrm{n} / \mathrm{a}$ & $\mathrm{n} / \mathrm{a}$ \\
\hline Lee. et al. [28] & $\begin{array}{l}\text { Analysis of readiness of predictive tool for } \\
\text { manufacturing services transformation }\end{array}$ & $\mathrm{n} / \mathrm{a}$ & $\mathrm{n} / \mathrm{a}$ \\
\hline Lee et al. [27] & $\begin{array}{l}\text { Propose a cyber-physical system architecture in } 5 \\
\text { layers }\end{array}$ & $\mathrm{n} / \mathrm{a}$ & $\mathrm{n} / \mathrm{a}$ \\
\hline Lee et al. [26] & Architecture for efficient energy management & $\mathrm{n} / \mathrm{a}$ & $\mathrm{n} / \mathrm{a}$ \\
\hline Lee et al. [29] & $\begin{array}{l}\text { Lit. review on knowledge management in smart } \\
\text { factory }\end{array}$ & $\mathrm{n} / \mathrm{a}$ & $\mathrm{n} / \mathrm{a}$ \\
\hline Leitão et al. [30] & High level architecture for smart factory & $\mathrm{n} / \mathrm{a}$ & $\mathrm{n} / \mathrm{a}$ \\
\hline $\begin{array}{l}\text { Miškuf \& Zolotova } \\
\text { [31] }\end{array}$ & $\begin{array}{l}\text { Case study on data exploration software } \\
\text { implementation }\end{array}$ & $\mathrm{n} / \mathrm{a}$ & $\mathrm{n} / \mathrm{a}$ \\
\hline $\begin{array}{l}\text { Neuböck \& Schrefl } \\
\text { [32] }\end{array}$ & Dimensional modelling applied to material planning & $\mathrm{n} / \mathrm{a}$ & $\mathrm{n} / \mathrm{a}$ \\
\hline Niño et al. [33] & Pilot study of equipment data real-time analysis & Ongoing; needs to be ex & Functional \\
\hline Oneto et al. [34] & $\begin{array}{l}\text { Data driven model for vessel monitoring state } \\
\text { prediction }\end{array}$ & $\mathrm{n} / \mathrm{a}$ & $\mathrm{n} / \mathrm{a}$ \\
\hline Oses et al. [35] & $\begin{array}{l}\text { Reduction of the range of prediction interval in } \\
\text { energy savings measurement }\end{array}$ & $\begin{array}{l}\text { Need to include more factors for } \\
\text { better prediction }\end{array}$ & Information \\
\hline Park [36] & $\begin{array}{l}\text { Success factors and expected effects of connected } \\
\text { factory }\end{array}$ & $\mathrm{n} / \mathrm{a}$ & $\mathrm{n} / \mathrm{a}$ \\
\hline Rix et al. [37] & Framework for die casting real time monitoring & $\begin{array}{l}\text { Need to link information } \\
\text { company wide }\end{array}$ & Business \\
\hline Shafiq et al. [39] & $\begin{array}{l}\text { Present a technical framework for an intelligent } \\
\text { factory }\end{array}$ & $\mathrm{n} / \mathrm{a}$ & $\mathrm{n} / \mathrm{a}$ \\
\hline $\begin{array}{l}\text { Ternoven } \quad \& \\
\text { Heikkilä [40] }\end{array}$ & Literature review on data mining and analysis in IIoT & $\begin{array}{l}\text { Include social networking and } \\
\text { human interactions in DM }\end{array}$ & Business \\
\hline Wang et al. [42] & Framework for big data analysis and ship monitoring & $\mathrm{n} / \mathrm{a}$ & $\mathrm{n} / \mathrm{a}$ \\
\hline Wang et al. [43] & $\begin{array}{l}\text { Description and application of a smart factory; RFID } \\
\text { tracking demonstration }\end{array}$ & $\begin{array}{l}\text { Technical challenges to the smart } \\
\text { factory implementation }\end{array}$ & Asset \\
\hline Wieland et al. [44] & $\begin{array}{l}\text { Low cost and flexible ruled-based assistant for } \\
\text { manufacturing }\end{array}$ & Need to implement and evaluate & Functional \\
\hline Wuest et al. [45] & $\begin{array}{l}\begin{array}{l}\text { Machine learning clustering to monitor } \\
\text { manufacturing quality }\end{array} \\
\end{array}$ & $\begin{array}{l}\text { Need to include all known } \\
\text { parameters; complex model }\end{array}$ & Information \\
\hline $\mathrm{Xu}$ et al. [46] & $\begin{array}{l}\text { Real time visual assembly line performance analysis } \\
\text { by adapting Marey's graph }\end{array}$ & $\begin{array}{l}\text { Limits to the complexity of data } \\
\text { that can be displayed }\end{array}$ & Information \\
\hline Yoon et al. [47] & $\begin{array}{l}\text { Technical architecture and requirements for a Smart } \\
\text { Factory }\end{array}$ & $\mathrm{n} / \mathrm{a}$ & $\mathrm{n} / \mathrm{a}$ \\
\hline Yu et al. [48] & Automated real time equipment monitoring & $\begin{array}{l}\text { Need to further examine practical } \\
\text { viability }\end{array}$ & Functional \\
\hline
\end{tabular}

